\title{
Penggunaan Media Kartu Bergambar Sebagai Upaya Meningkatkan Minat Baca Anak Usia Dini di Pos Paud Mutiara Bundaku Malang
}

\author{
Loesita Sari \\ Program Studi Pendidikan Ekonomi dan Kewirausahaan \\ IKIP Budi Utomo Malang \\ Jalan Citandui 46 \\ Yulita Pujiharti \\ Program Studi Pendidikan Ekonomi dan Kewirausahaan \\ IKIP Budi Utomo Malang \\ Jalan Citandui 46 \\ Naniek Kuscahyani \\ Program Studi Pendidikan Ekonomi dan Kewirausahaan \\ IKIP Budi Utomo Malang \\ Jalan Citandui 46
}

\begin{abstract}
The purpose of this study is to determine the use of the media card image as an effort to increase students's Interest in reading Pos Paud Mutiara Bundaku Malang. This study used a comparative approach with research and development and statistic analysis. The Subject involved the students of Pos Paud Mutiara Bundaku Malang which consisted of 13 students. The Sources of data were documents containing result of pretest and postest methods, interviews and obsevation. Based on the research analysis, it was found that the children's interst in reading media picture card increased to be 7.68 better than before at the score of 69.23 .
\end{abstract}

Keyword : card picture, media, reading, interest

Pendidikan Anak Usia Dini merupakan salah satu bentuk penyelenggaraan pendidikan yang menitik beratkan pada peletakan dasar ke arah pertumbuhan, perkembangan fisik (koordinasi motorik kasar dan halus), dan kecerdasan (daya pikir, daya cipta, kecerdasan emosi, kecerdasan spiritual) (Netti Herawati, 2005: 7). Hal ini dipertegas dalam UU Sisdiknas 2003 Bab 1 Pasal 1 Ayat 14 yang menyatakan bahwa Pendidikan Anak Usia Dini adalah salah satu pembinaan yang ditujukan kepada anak sejak lahir sampai dengan usia enam tahun yang dilakukan melalui pemberian rangsangan pendidikan untuk membantu pertumbuhan dan perkembangan jasmani dan rohani agar anak memiliki kesiapan dalam memasuki pendidikan lebih lanjut. Pendidikan yang diberikan pada anak usia dini sebaiknya disesuaikan dengan usia dan tahap perkembangannya.

Pendidikan Anak Usia Dini merupakan proses pengembangan kemampuan yang paling mendasar bagi setiap anak. Oleh karena itu, peran guru sangat berpengaruh besar terhadap keberhasilan proses pembelajaran. Guru harus mampu mengoptimalkan semua aspek perkembangan anak usia dini. untuk mengikuti perubahan pola pendidikan yang ada. Guru harus mampu melakukan inovasi dalam dunia pendidikan, sehingga guru harus mampu menciptakan pembelajaran yang efektif untuk menanamkan konsep-konsep dasar pada anak. Masa usia dini adalah masa yang sangat fundamental bagi perkembangan anak, masa yang penuh dengan kejadian-kejadian penting yang unik dan menjadi dasar bagi kehidupan seseorang dimasa dewasa merupakan masa peka terhadap keteraturan lingkungan dan mengeksplorasi lingkungan (Slamet Rahardjo, 2006:5). Yuliani Nurani Sujiono, dkk (2005: 35) mengemukakan bahwa pada masa ini hampir seluruhpotensianakmengalamimasapekauntuk tumbuh dan berkembang secara tepat sesuai 
dengan tahap perkembangan usia anak. Tahap perkembangan ini hanya berlangsung sekali dalam kehidupannya, sehingga akan berdampak pada penumpukan tugas perkembangan anak yang tidak mungkin diulangi pada tahap-tahap perkembangan selanjutnya. Oleh karena itu, anak-anak sejak dini dibekali pendidikan yang berlandaskan konsep-konsep agama sebagai pondasi agar menjadi manusia yang mampu mengembangkan seluruh potensi dirinya sendiri dengan baik. Anak pada usia itu membutuhkan rangsangan, dorongan atau motivasi, agar anak mempercepat perkembangannya baik aspek perkembangan pada umumnya atau aspek perkembangan bahasa. Program anak usia dini harus bisa mempengaruhi kemauan anak untuk membaca, dengan jalan merencanakan secara hati-hati sebuah kurikulum seni bahasa yang komprehensif. Program ini berfungsi untuk memperluas pengalaman pembelajaran bahasa anak-anak tersebut baik secara oral atau tertulis. Minat baca sangat penting ditumbuhkan pada anak sedini mungkin karena banyak sekali manfaatnya baik bagi anak-anak itu sendiri maupun bagi orang tua dalam menjalankan peranan tersebut orang tua yang bertamnggung jawab mendidik anak(Anna Yulia,2005:1). membaca permulaan adalah kegiatan berbahasa yang secara aktif menyerap informasi atau pesan yang disampaikan melalui media tulis, seperti buku, artikel, modul, surat kabar, atau media tulis.

Cochorane 1984 dalam Slamet Suyanto (2005: 168) ada lima tahap kemampuan membaca pada anak, yakni :

a. Tahap Magis (Magical Stage)

Pada tahap ini, anak belajar memahami fungsi dari bacaan. Anak mulai menyukai bacaan, menganggap bacaan itu penting, sering ia menyimpan bacaan yang anak sukai dan membawanya kemana ia mau.

b. Tahap Konsep Diri (Self-concept Stage)

Pada tahap ini anak memandang dirinya sudah dapat membaca. Anak sering menerangkan isi atau gambar dalam buku yang anak sukai kepada anak lain seakan ia sudah mencapai tahap ini.

c. Tahap Membaca Peralihan (Bridging Reader Stage) Anak mulai mengingat huruf atau kata yang sering anak jumpai, misalnya dari buku cerita yang sering diceritakan orang tuanya.

d. Tahap Membaca Lanjut (Take-off Reader Stage) Anak mulai sadar akan fungsi bacaan dan cara membacanya. e. Tahap Membaca Mandiri (Independent Reader) Anak mulai dapat membaca secara mandiri.

Azhar Arsyad (2002:119) flashcard atau kartu bergambar adalah kartu kecil yang berisi gambar, teks, atau tanda simbol mengingatkan atau menuntun siswa kepada sesuatu yang berhubungan dengan gambar tersebut. Tujuan Penelitian

1. Untuk mengetahui pengembangan media gambar pada pembelajaran anak usia dini

2. Untuk mengetahui minat baca anak usia dini sebelum menggunakan media gambar

3. Untuk mengetahui minat baca anak usia dini sesudah menggunakan media gambar

4. Untuk mengetahui pengaruh minat baca anak usia dini dengan menggunakan media gambar

\section{METODE PENELITIAN}

Penelitian ini merupakan jenis penelitian pengembangan yang berorientasi pada pengembangan produk. Research and Development (R\&D) adalah metode penelitian yang digunakan untuk menghasilkan produk tertentu dan menguji keefektifan produk tertentu (Sugiyono, 2012: 406). Van Dallen dalam Arikunto (2002: 236-237) menyebutkan bahwa "Penelitian komparasi yaitu ingin membandingkan dua atau tiga kejadian dengan melihat penyebabpenyebabnya".

\begin{tabular}{|c|c|}
\hline \multicolumn{2}{c}{ Variabel Penilaian } \\
\hline$X$ & $\begin{array}{c}\text { Kelompok } \\
\text { Eksperimen }\end{array}$ \\
\hline$Y$ & Kelompok Kontrol \\
\hline
\end{tabular}

Keterangan :

$X=$ ada treatment (media gambar)

$\mathrm{Y}=$ tidak ada treatment

Dalam penelitian pengembangan ini, penulis mengacu pada pedoman penelitian pengembangan menurut Borg \& Gall (Nana Syaodih, 2013: 169). Borg \& Gall menjelaskan sepuluh prosedur penelitian pengembangan yang akan dijadikan pedoman dalam penelitian ini, sebagai berikut:

1. Melakukan penelitian pendahuluan dan pengumpulan informasi (research and information collecting)

2. Melakukan perencanaan (planning) 
3. Mengembangkan produk awal (develop preliminary from of product)

4. Melakukan uji coba permulaan (preliminary field testing)

5. Melakukan revisi terhadap produk utama (main produk revision)

6. Melakukan uji lapangan utama (main field testing)

7. Melakukan revisi terhadap produk operasional (operational produk revision)

8. Melakukan uji lapangan operasional (operational field testing)

9. Melakukan revisi terhadap produk akhir (final product revision)

10. Mendesiminasikan mengimplementasikan produk(desiminatiion and implementation)

Validasi dalam penelitian ini dilakukan oleh:

\section{Ahli media \& materi}

Ahli media \& materi yang dimaksud adalah guru Taman Kanak-kanak yang berperan untuk menilai media \& materi pada pembelajaran anak usia dini. Validasi dilakukan dengan menggunakan angket tentang media \& materi yang akan diberikan kepada ahli media \& materi.

Kisi-Kisi Intrumen untuk Ahli Materi \& Media

\begin{tabular}{|c|c|c|c|}
\hline No & Aspek & Indikator & Jumlah \\
\hline \multicolumn{4}{|c|}{ Aspek bahasa dan gambar } \\
\hline 1. & $\begin{array}{l}\text { Keba- } \\
\text { hasaan }\end{array}$ & $\begin{array}{l}\text { a. Kejelasan bahasa yang di } \\
\text { gunakan } \\
\text { b. Kemudahan huruf untuk } \\
\text { di baca }\end{array}$ & $\begin{array}{l}1 \\
1\end{array}$ \\
\hline \multirow[t]{8}{*}{2.} & \multirow{8}{*}{$\begin{array}{l}\text { Gambar } \\
\text { Ilustrasi }\end{array}$} & \multirow[t]{2}{*}{ a. Kualitas gambar } & 1 \\
\hline & & & 1 \\
\hline & & \multirow{2}{*}{$\begin{array}{l}\text { b. Ukuran gambar yang di } \\
\text { gunakan }\end{array}$} & 1 \\
\hline & & & 1 \\
\hline & & $\begin{array}{l}\text { c. Kesesuaian gambar dengan } \\
\text { obyek asli }\end{array}$ & 1 \\
\hline & & \multicolumn{2}{|l|}{$\begin{array}{l}\text { d. Kesesuaian gambar dengan } \\
\text { materi }\end{array}$} \\
\hline & & \multicolumn{2}{|l|}{ e. Letak gambar pada media } \\
\hline & & \multicolumn{2}{|l|}{ f. Warna gambar padsa media } \\
\hline No & Aspek & Indikator & Jumlah \\
\hline \multicolumn{4}{|c|}{ Aspek Penyajian } \\
\hline & \multirow{2}{*}{$\begin{array}{c}\text { Teknik } \\
\text { Penya- } \\
\text { jian }\end{array}$} & a. Kemenarikan Media & 1 \\
\hline & & b. Daya dukung media & 1 \\
\hline
\end{tabular}

\begin{tabular}{llll}
\hline \multicolumn{3}{c}{ Aspek Kegrafisan } \\
\hline 1 & $\begin{array}{c}\text { Ukuran } \\
\text { Media }\end{array}$ & Kesesuaian ukuran media & 1 \\
\hline 2 & De- & a. Ketepatan jenis kertas cetak & 2 \\
& sain & b. Kesesuaian bentuk Kartu & 2 \\
& Media & bergambar & 3 \\
& c. Kesesuaian huruf dengan & 1 \\
& & d. Garakteristik anak & 1 \\
& e. Warna pada gambar & 20 \\
\hline
\end{tabular}

Skala Persentase Kelayakan Media

\begin{tabular}{cc}
\hline Persentase pencapaian & Interpretasi \\
\hline $76-100 \%$ & Layak \\
$56-75 \%$ & Cukup layak \\
$40-55 \%$ & Kurang layak \\
$0-39 \%$ & Tidak layak \\
\hline
\end{tabular}

Teknik analisis data penelitian merupakan salah satu langkah yang sangat penting dalam sebuah proses penelitian karena disinilah hasil penelitian akan terlihat. Analisis data mencakup seluruh kegiatan mengklarifikasi, menganalisa, memakai dan menarik kesimpulan dari semua data yang terkumpul dalam tindakan (Suharsimi Arikunto, 2002: 244). Karena sample yang di gunakan kecil < dari 30 maka di gunakan uji $\mathrm{T}$ dengan rumus sebagai berikut:

$$
t_{o}=\frac{M_{X}-M_{Y}}{\sqrt{\left(\frac{S D_{X}}{\sqrt{N-1}}\right)^{2}+\left(\frac{S D_{Y}}{\sqrt{N-1}}\right)^{2}}}
$$

(Hartono,2012 : 208)

\section{Keterangan:}

$t_{0}:$ T-test

$\mathrm{M}$ : Mean

SD : Standar Deviasi

$\mathrm{N}$ : Jumlah Sampel

Untuk menganalisis data, menggunakan alat bantu software komputer program SPSS (Statistical Product for Service Solution) 20 for windows.

Kriteria Penerimaan dan Penolakan Hipotesa Jika t-signifikan $\geq 0,05$ maka $\mathrm{H}_{\mathrm{o}}$ di terima $\mathrm{H}_{\mathrm{a}}$ di tolak yang berarti tidak ada pengaruh.Jika t-signifikan $\leq$ 0,05 maka $\mathrm{H}_{\mathrm{o}}$ di tolak $\mathrm{H}_{\mathrm{a}}$ di terima berarti ada pengaruh pada penggunaan media bergambar. Singgih $(2015: 247)$ 
50 | Loesita Sari, dkk., Penggunaan Media Kartu Bergambar sebagai ...

\section{HASIL DAN PEMBAHASAN}

Dalam studi pendahuluan, peneliti melakukan proses pengumpulan informasi dengan menganalisis kebutuhan pembelajaran anak dengan cara mengobservasi, wawancara dengan guru kelas kelompok B. Wawancara dilakukan untuk mendapatkan informasi tentang permasalahan dan proses pembelajaran di kelas. Beberapa jawaban dari guru mengenai media pembelajaran adalah sebagai berikut. Dalam pembelajaran guru menyatakan berusaha untuk menggunakan media benda konkrit. Guru telah mengetahui bahwa media benda konkrit sangat tepat untuk anak dan membuat anak mudah paham dan mengerti tentang materi yang diberikan guru. Sebagai contoh untuk pembelajaran tema tanaman subtema biji-bijian, guru meminta anak untuk membawa biji-bijian dari rumah untuk pembelajaran di sekolah. Dari studi pendahuluan tentang perlunya memproduksi sebuah media untuk menstimulasi aspek bahasa anak Paud kelompok B, maka pengembang membuat sebuah media kartu bergambar tentang tema binatang dan tanaman untuk anak Paud. Materi yang dipilih disesuaikan dengan kurikulum anak Paud kelompok B. Dengan desain menggunakan warna-warna cerah, ukuran dan gambar disesuaikan karakteristik anak Paud dan mudah digunakan. Media kartu bergambar ini dikembangkan dengan tujuan untuk menghasilkan suatu media yang menarik yang dapat mengembangkan aspek bahasa anak Paud. Setelah melakukan analisis pembelajaran, peneliti menganalisis produk atau media yang akan dikembangkan.

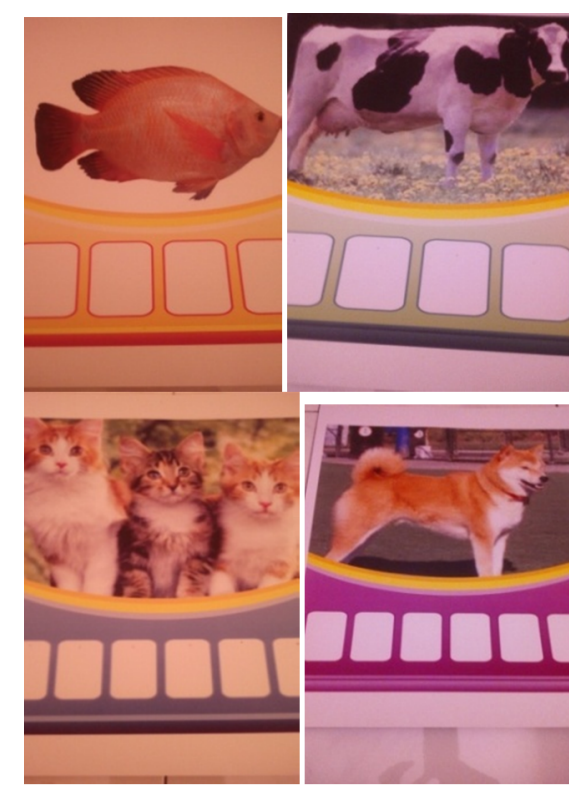

Setelah peneliti melakukan uji coba sebelum menggunakan media bergambar maka dapat di lihat tingkat minat baca anak pada tabel dibawah ini

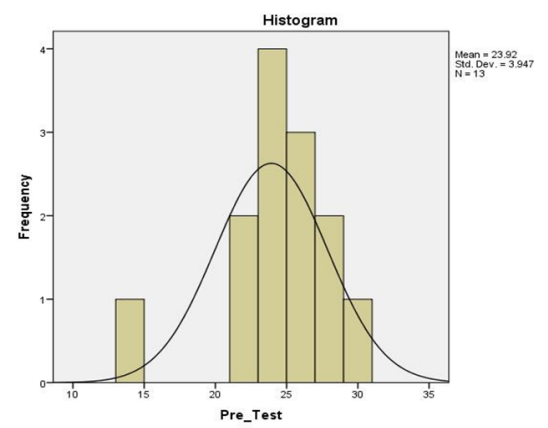

Gambar 4.1 Data Histogram Normal Minat Baca sebelum menggunakan media gambar

\section{Output bagian ketiga (histogram)}

setelah peneliti melakukan uji coba sebelum menggunakan media bergambar maka dapat di lihat tingkat minat baca anak pada tabel dibawah ini :

\begin{tabular}{cccc}
\hline pencapaian & Interprestasi & Jumlah & $\%$ \\
\hline $39-48$ & Sangat Tinggi & 3 & 69,23 \\
$29-38$ & Tinggi & 9 & 23,08 \\
$19-28$ & Sedang & 1 & 7,69 \\
$9-18$ & Rendah & - & - \\
Jumlah & & 13 & 100 \\
\hline
\end{tabular}

Gambar 4.2 Data Histogram Normal sesudah menggunakan media bergambar

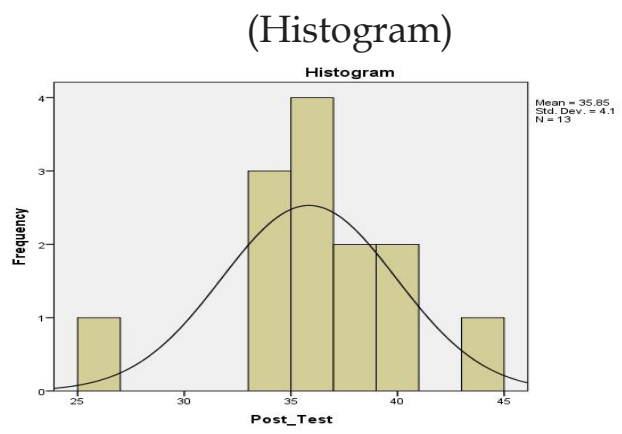

Gambar 4.2 Data Histogram Normal sesudah menggunakan media bergambar (Histogram)

\section{Hipotesis}

Hipotesis yang diajukan adalah : Jika nilai signifikan $>0,05$, maka Ho diterima $\mathrm{H}_{\mathrm{a}}$ 
di tolak tidak ada pengaruh penggunaan media gambar

Jika nilai signifikan $<0,05$, maka Ho ditolak $\mathrm{H}_{\mathrm{a}}$ di terima ada pengaruh pada penggunaan media bergambar.

\section{Hasil uji Hipotesis}

Nilai t hitung adalah sebesar 1.782 dengan sig 0.000. Karena sig $<0.05$ maka dapat disimpulkan bahwa $\mathrm{H}_{\mathrm{o}}$ ditolak dan $\mathrm{H}_{\mathrm{a}}$ diterima adalah berbeda (tidak sama). Dengan demikian dapat dinyatakan bahwa Penggunaan Media Kartu Bergambar sangat efektif untuk meningkatkan minat baca siswa.

\section{KESIMPULAN DAN SARAN}

Pengembangan media kartu bergambar untuk anak Paud dalam penelitian ini dilaksanakan berdasarkan langkah-langkah sistematis sebagai berikut: penelitian pendahuluan, melakukan perencanaan, pengembangan dan produksi, validasi ahli media dan ahli materi (media kartu bergambar ini termasuk dalam kriteria "Layak". uji coba lapangan media kartu bergambar berpengaruh terhadap perkembangan bahasa anak (media kartu bergambar ini untuk aspek keaktifan/ partisipasi, ketertarikan anak, dan efek strategi pembelajaran termasuk ke dalam kategori "Layak" dengan presentasi 89,29\%). Secara keseluruhan media kartu bergambar ini layak digunakan sebagai media pembelajaran

Sebelum Penggunaan media bergambar minat baca anak rendah dengan nilai 7,69\%

Setelah menggunakan media bergambar minat baca anak sangat tinggi dengan nilai $69,23 \%$

Adanya pengaruh pada minat baca anak sebelum dan sesudah menggunakan media bergambarpada anak pos paud Mutiara
Bundaku Kesatrian dalam Malang. Hal ini dapat ditunjukkan dari hasil perhitungan dengan uji-t pada taraf signifikansi 0,00 diperoleh harga thitung sebesar 1.782 ,karena sig < 0,05 maka minat baca anak sesudah menggunakan media gambar lebih tinggi di banding dengan sebelum menggunakan media gambar.

Berdasarkan hasil penelitian telah dinyatakan media bergambar untuk anak Paud sudah divalidasi oleh ahli dan layak setelah diujicobakan, maka disarankan:

Bagi Kepala Pos Paud, agar merencanakan pengadaan media bergambar ini sebagai salah satu media pembelajaran di Paud.

Bagi guru Paud, dapat memanfaatkan media bergambar ini sebagai media pembelajaran dalam proses pembelajaran bisa digunakan saat kegiatan apersepsi, inti ataupun penutup.

Bagi Pengembangan Selanjutnya, dapat mengembangkan media kartu bergambar dengan membahas gambar yang lain

\section{DAFTAR PUSTAKA}

Adhim Faudzil Mohammad . 2004. Membuat Anak Gila Membaca. Bandung: PT. Mizan Pustaka.

Anna Yulia. 2005. Cara Menumbuhkan Minat Baca Anak. Jakarta: PT. Elex Media Komputindo.

Arikunto Suharsimi.2002. Prosedur Penelitian Suatu Pendekatan Praktek.Jakarta: Rineka Cipta

Maimunah Hasan. 2007. Pendidikan Anak Usia Dini. Yogya: Diva Press.

Punaji Setyosari. 2012. Metode Penelitian Pendidikan dan Pengembangan. Jakarta: Kencana

Prasetyono Sunar Dwi S. 2008 . Rahasia Mengajarkan Gemar Membaca Pada Anak Usia Dini. Yogyakarta: Think 
52 | Loesita Sari, dkk., Penggunaan Media Kartu Bergambar sebagai ... 